\title{
Evolución del uso del hipertexto en la prensa española (2002-2016)
}

\section{Evolution of the use of hypertext in the Spanish press (2002-2016)}

\author{
Paz Orero; Bernardino J. Cebrián-Enrique
}

Cómo citar este artículo:

Orero, Paz; Cebrián-Enrique, Bernardino J. (2019). "Evolución del uso del hipertexto en la prensa española (2002-2016)". El profesional de la información, v. 28, n. 2, e280225.

https://doi.org/10.3145/epi.2019.mar.25

Artículo recibido el 09-01-2018

Aceptación definitiva: 31-01-2019

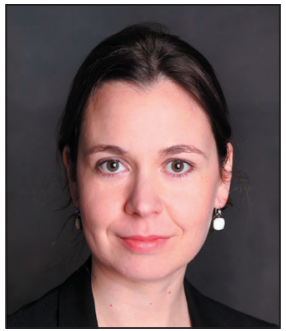

Paz Orero $\bowtie$

http://orcid.org/0000-0001-8520-5512

Institut Valencià de Cultura (IVC)

Polígono Acceso Ademuz, s/n. 46100

Burjassot (Valencia), España

orero_paz@gva.es

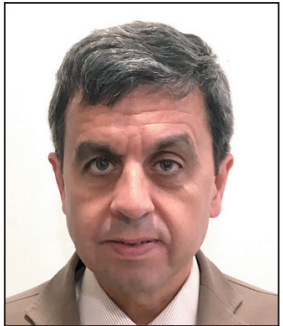

Bernardino J. Cebrián-Enrique http://orcid.org/0000-0001-9722-5481

Universidad Cardenal Herrera - CEU Facultad de Humanidades y Ciencias de la Comunicación

Luis Vives, 1. 46115 Alfara del Patriarca

(Valencia), España

dcebrian@uch.ceu.es

\section{Resumen}

Análisis de la evolución del uso del hipertexto en la prensa digital española. Dos décadas después de la aparición de las primeras ediciones web de los diarios españoles, se estudia el grado de madurez, los cambios y las tendencias en el empleo de los enlaces semánticos. Para lograr este objetivo, se realiza un análisis empírico longitudinal retrospectivo de la utilización del hipertexto en la práctica profesional entre los años 2002 y 2016 a través de las hemerotecas digitales de seis cabeceras generalistas. El estudio de periódicos de referencia en la prensa española se complementa con medios locales, apenas tenidos en cuenta en las investigaciones sobre hipertexto hasta ahora realizadas. En total, se examinan 22.296 enlaces semánticos que aparecen en 4.620 noticias publicadas en portada y se estudian en profundidad los 4.830 vínculos incluidos en el cuerpo o relato informativo.

\section{Palabras clave}

Hipertexto; Hipertextualidad; Enlaces semánticos; Prensa digital; Medios de comunicación; Ciberperiodismo; Periodismo digital; Periodismo; Investigación.

\begin{abstract}
Analysis of the evolution of the use of hypertext on Spanish digital newspapers. Two decades after the first Spanish news sites, the authors studied the level of maturity of the use of semantic links as well as the most significant changes and trends when using these resources. To achieve this objective, a retrospective longitudinal empirical analysis of the use of hyperlinks is performed, covering the professional practice between 2002 and 2016. The research included six online news: three top-ranked national newspapers, and three local news sites, an area barely studied among researchers studying hypertext. The overall number of semantic links is 22,296 , all of them included in 4,620 home-page news stories. 4,830 links appearing within the text body received an extensive analysis.
\end{abstract}

\section{Keywords}

Hypertext; Semantic links; Digital newspapers; Media; Cyberjournalism; Digital journalism; Journalism; Research.

\section{Financiación}

Esta investigación se ha realizado en el marco del proyecto Oportunidades y retos del periodismo en los entornos abiertos. Estudio de las voces de la sociedad en torno a los medios tradicionales y los sitios participativos de nueva generación, del que es miembro el investigador Bernardino J. Cebrián-Enrique (referencia CSO2016-80703-R Fondos Feder), financiado por el Ministerio de Economía y Competitividad de España. 


\section{Introducción}

Desde el inicio de la Web y los primeros diarios en internet, los teóricos alumbraron las posibilidades que la hipertextualidad podía ofrecer al periodismo. A finales de la década de los 90 y en los inicios del nuevo siglo se realizaron las primeras contribuciones teóricas sobre la estructura y el discurso hipertextual de las noticias. Estos estudios trataron de crear un modelo propio asumiendo hallazgos previos de los campos de la literatura, la lingüística, la sociología, la psicología y la documentación (Díaz-Noci; Salaverría, 2003; Masip et al., 2010).

De entre todos ellos, las teorías literarias y lingüísticas fueron las más influyentes, puesto que incidían en dos aspectos aplicables al periodismo (Landow, 1995; Murray, 2000; Engebretsen, 2006):

- la urgencia de reconfigurar la narrativa y retórica conforme al carácter del hipertexto;

- las enormes posibilidades de interactividad entre emisor y receptor.

A su vez, investigadores de otros países (Nielsen, 1995; McAdams; Berger, 2001; Deuze, 2001; Paul; Fiebich, 2005; Doherty, 2014), continuaron incidiendo en las posibilidades del fenómeno, elaborando modelos de estructura del hipertexto periodístico, tratando de encontrar nuevas estructuras narrativas para su uso en los medios.

La investigación empírica y comparativa ha sido escasa y, obviamente, paralela a la implantación y desarrollo hipertextual en la práctica profesional. Respecto a este tipo de análisis, cabe destacar los estudios iniciales de Deuze (2003) y Engebretsen (2006) en Escandinavia; Quandt (2008) con una comparativa entre medios de Europa y Estados Unidos; o Van-der-Wurff y Lauf (2006). Todos ellos son estudios de momentos específicos o instantáneas que constatan un desarrollo lento de la hipertextualidad y que aportan recomendaciones sobre su uso (cantidad, destino, necesidades del usuario, selección de recursos, etc.) en la práctica periodística.

Karlsson, Clerwall y Örnebring (2015) presentaron uno de los escasísimos trabajos longitudinales sobre uso de hipervínculos en el que se demuestra que el impacto global de los enlaces se había mantenido estable en el período analizado y que los enlaces internos, sin dejar de ser en su mayor parte los más presentes, disminuían en importancia, mientras que aumentaban los vínculos externos.

Aunque durante la mayor parte de las últimas dos décadas los académicos de los medios de comunicación han defendido el uso de hipervínculos y su integración dentro de la práctica del periodismo, existe una carencia de investigaciones exhaustivas de revisión proyectadas hacia el pasado reciente digital y de estudios que profundizan en la dinámica de las redacciones y las motivaciones que expliquen

“los procesos de cambio, evolución, adaptación o incluso involución en dichas prácticas, más allá de las visiones utópicas de los primeros tiempos de investigación sobre comunicación digital” (Díaz-Noci, 2018).

Las razones exactas detrás de la práctica hipertextual también han sido relativamente inexploradas. De-Maeyer y Holton constataron que los enlaces se relacionan con la transparencia de la producción periodística, con la recepción de los usuarios y con las circunstancias económicas en las que se producen las noticias (De-Maeyer; Holton, 2016), y que su uso real no se corresponde a la percepción de los periodistas (De-Maeyer, 2012; 2011).

\subsection{Investigación del hipertexto en la prensa española}

Los primeros trabajos sobre ciberperiodismo en España se esforzaban en exponer las enormes posibilidades que proporcionaban las características intrínsecas de la Red, entre ellas el hipertexto, y proponían nuevas formas de narración periodísticas que se adaptaran a ella (Armañanzas; Díaz-Noci; Meso, 1996; Armentia-Vizuete; Elexgaray-Arias; Pérez-Fuentes, 1999; Salaverría, 1999; Salaverría et al., 2005; Díaz-Noci, 2001).

La mayor parte de los estudios son propuestas teóricas de taxonomía de hipervínculos (Cantos-Gómez; Martínez-Méndez; Moya-Martínez, 1994; Codina, 1997; 2000) y de análisis de la estructura hipertextual (Díaz-Noci; Salaverría, 2003; Codina, 2003; Barbosa; Mielniczuk, 2011) que pueden aplicarse al periodismo (Palacios; Díaz-Noci, 2007).

Sin embargo, no abundan los estudios empíricos sobre el grado de aplicación de los hipervínculos semánticos en la prensa española:

"La brecha entre la teoría y su aplicación práctica permanece abierta y casi inexplorada" (Arias-Robles; García-Avilés, 2018).

Las escasas investigaciones sobre casos reales del empleo de los hipervínculos en los medios españoles (Pérez-Marco, 2003; Salaverría et al., 2004; Diezhandino-Nieto, 2008; Larrondo-Ureta, 2005; 2009; Fondevila-Gascón, 2011; Fondevila-Gascón; Segura-Jiménez, 2012; Fondevila-Gascón; Beriain-Bañares; Del-Olmo-Arriaga 2013; Larrondo-Ureta; Díaz-Noci, 2014; Arias-Robles, 2016; Arias-Robles; García-Avilés, 2018) constituyen valiosos estudios comparados de períodos puntuales que han ido constatando de manera unánime, tras una lenta y variable adaptación, la utilización creciente y progresiva del número de hipervínculos, aunque su práctica adolece de diversas carencias. Entre ellas:

- el insignificante número de enlaces externos,

"lo que refleja cierta endogamia de la industria periodística, aunque sea por causas comerciales de la cantidad de tráfico amarrado" (Fondevila-Gascón; Beriain-Bañares; Del-Olmo-Arriaga, 2013); 
- el tipo del nodo de destino que busca la actualidad más ligada temporalmente a la noticia, últimamente a través de los repositorios de artículos, y no tanto la contextualización de fondo (Diezhandino, 2008; Arias-Robles; García-Avilés, 2018).

En el estudio del hipertexto en el periodismo también hay reflexión crítica sobre el mismo (Carr, 2011) y se cuestiona el uso de los hipervínculos en los medios de comunicación. Recientes recomendaciones de los grandes medios europeos van en la línea de restringir el uso de los vínculos debido a las repercusiones, tanto en la calidad del producto informativo como en materia de audiencia, tráfico y posicionamiento web. Y esta tendencia restrictiva parece favorecida por el consumo masivo de información a través de los dispositivos móviles donde la usabilidad está limitada por el tamaño y la precisión de la pantalla (Arrese-Reca, 2016; Arias-Robles; García-Avilés, 2017).

Cuando se han cumplido dos décadas de la aparición de las primeras ediciones digitales de los diarios españoles parece pertinente investigar por primera vez la evolución histórica del hipertexto mediante un estudio longitudinal retrospectivo con el propósito de lograr una perspectiva cronológica completa del fenómeno, descubrir cómo han evolucionado las prácticas hipertextuales y detectar cambios y tendencias. Además de dotar al estudio del carácter longitudinal, interesa incluir cabeceras de la prensa digital regional y local, por su escasa atención en investigaciones previas.

\section{Objetivo}

El objetivo de la investigación es el estudio de la situación actual y de la evolución del hipertexto informativo en las noticias de portada de la prensa española. El estudio pretende aportar datos indicativos del grado de presencia, aplicación y desarrollo de los enlaces semánticos desde el año 2002 hasta el 2016.

Los objetivos específicos buscan:

- Determinar el uso y la transformación en el tiempo de los hipervínculos semánticos en las noticias de portada.

- Indagar en la cantidad, tipo, destino y singularidad de los enlaces según las características de las diversas cabeceras.

\section{Metodología}

El carácter descriptivo retrospectivo de la investigación exige que, entre los medios de comunicación digitales generalistas españoles, se consideren idóneas aquellas cabeceras que cumplan con dos requisitos imprescindibles:

- contar con una hemeroteca web de libre acceso que permita consultar la publicación digital mediante navegación cronológica o browsing;

- que el medio tenga una trayectoria de al menos un lustro de presencia en la Red, con tal de poder observar adecuadamente la evolución hipertextual.

Se procedió a un muestreo no probabilístico estratégico del universo de cabeceras digitales españolas, aunque introduciendo cuatro criterios objetivos:

- Soporte de edición: la muestra debe contemplar tanto diarios nativos digitales como otros que mantienen una versión en papel.

- Zona geográfica: la selección debe incluir medios generalistas de distinto alcance territorial. La mayor parte de los estudios sobre el grado de aplicación del hipertexto en la prensa española están centrados en medios estatales y apenas se ha estudiado su implantación en la prensa autonómica o local.

- Audiencia: los periódicos digitales generalistas deben ser líderes de audiencia. Se priorizan aquellos con mayor número de usuarios únicos en su área, según la certificación oficial de comScore, la compañía auditora de audiencias online, correspondiente a los meses de septiembre y octubre de 2015.

- Heterogeneidad en la propiedad empresarial: los medios analizados deben pertenecer preferentemente a grupos editoriales distintos, lo que permitirá analizar las rutinas productivas en un espectro lo más amplio posible de la prensa digital española.

De acuerdo con estos criterios, la muestra final la conformaron 6 medios generalistas, tres nacionales y tres locales:

- los 2 medios nacionales líderes con versión impresa (El país y El mundo);

- los 2 medios valencianos líderes con versión impresa (Las provincias y Levante-EMV);

- los 2 medios nativos digitales líderes en el ámbito nacional y en el valenciano, respectivamente (El confidencial y Valencia plaza).

Las tres cabeceras locales (Las provincias, Levante-EMV y Valencia plaza) son una muestra representativa de la Comunidad Valenciana, extrapolable a otras comunidades autónomas, que cumple los criterios fijados de soporte de edición diferenciado, liderazgo de audiencia y propiedad empresarial heterogénea.

Una vez determinada la muestra de cabeceras, debido a la enorme producción de información que estos medios generan diariamente, fue necesario establecer la selección de las piezas informativas que se someterían al análisis de contenido. Para ello se atendió a cuatro criterios:

- Ubicación: se escogieron los contenidos publicados en la portada de las cabeceras, ya que son las informaciones tratadas con mayor amplitud por su jerarquización como temas principales por parte del medio, lo que sugiere un tra- 
tamiento hipertextual más amplio y rico para el estudio. Cabe precisar que la portada es consultable de modo retrospectivo en todos los diarios seleccionados, excepto en valenciaplaza.com y en elpais.com en el período 2002-2011. En ambos periódicos, las hemerotecas no conservan este tipo de acceso y muestran una lista de noticias publicadas por día, aunque el tamaño de la tipografía permite identificar las que ocuparon ese lugar destacado.

- Franja horaria de inserción en portada: en el caso de que el diario ofrezca la posibilidad de revisar distintas versiones de portada -según hora de publicación- se opta por la de la tarde para asegurar la heterogeneidad en el grado de la elaboración e inmediatez de los contenidos y, en el caso de los diarios que editan en papel, para que esté más alejada de los contenidos que provienen del volcado de la edición impresa efectuado en la madrugada.

- Fecha de publicación de la pieza informativa: para contemplar el mayor período de tiempo posible y dar así el máximo alcance a este estudio longitudinal retrospectivo, se tiene en cuenta tanto la antigüedad de cada cabecera en la Red como la disponibilidad de sus fondos documentales digitales para acceder a las piezas que puedan ser objeto de análisis. Debido a estos dos condicionantes, el período temporal del estudio no es idéntico en todas las cabeceras de la muestra: El país y El mundo 2002-2016; Las provincias y Levante-EMV 2008-2016; El confidencial 2010-2016; y Valencia plaza 2010-2015.

Una vez establecidos los lapsos temporales, la ubicación en portada y franja horaria de publicación, se determinó la selección final de la muestra de las piezas informativas de portada a través de un muestreo probabilístico aleatorio por conglomerados polietápico para escoger los días a analizar y un muestreo aleatorio simple para la determinación de las piezas informativas.

Finalmente, el análisis se efectuó sobre 21 piezas informativas por semana, en los intervalos cronológicos anteriormente detallados por grupos de cabeceras, lo que supuso un total de 4.620 piezas informativas como muestra objeto de análisis. La muestra establecida para cada diario cumplía holgadamente el tamaño exigible para poblaciones infinitas (Spiegel; Stephens, 2009) y resultaba por tanto válida, representativa y significativa (nivel de confianza: 95\%, distribución: $50 \%$ y margen de error: 3-5\%).

Ante la inexistencia de propuestas metodológicas previas que se ajustaran de forma plena a todos los objetivos contemplados, se procedió al diseño de una ficha de análisis propia, incluyendo variables procedentes de las aportaciones de diversos investigadores (Codina, 2003; Diezhandino-Nieto, 2008; Fondevila-Gascón, 2014; Arias-Robles, 2015). En el diseño de la ficha se tuvo en cuenta que la unidad de análisis del estudio es doble:

- la primera de ellas es idéntica a la unidad de muestra: las piezas informativas incluidas en portada en los seis diarios seleccionados durante los períodos de análisis contemplados en la muestra;

- la segunda son los enlaces semánticos que aparecen en el relato informativo en cada una de las piezas estudiadas.

Una última consideración metodológica: se entiende por hipervínculo semántico:

- aquel que aparece en el cuerpo o relato periodístico y que permite enriquecer documentalmente la lectura;

- el que remite a otras noticias o contenidos estrechamente relacionados con el tema de la información principal pero que se sitúan fuera del cuerpo, bien en módulos inferiores, laterales o a través de destacados;

- el correspondiente a las etiquetas que indizan el contenido informativo y que envían a repositorios temáticos donde se conservan los documentos que han sido publicados por el diario y que previamente han sido indizados con ese término.

Queda fuera de la consideración de enlace semántico y por tanto no se incluyeron en la investigación, los vínculos a aquellos elementos que permiten opciones de acción o interacción del lector (dejar comentarios, imprimir el texto, compartir la información por correo electrónico o red social, etc.).

A continuación se presenta un resumen de los resultados obtenidos.

\section{Evolución cronológica por medios del número total de enlaces semánticos}

La hipertextualidad se ha ido incrementando y consolidando con los años en la prensa española, aunque no de manera constante sino de forma irregular y con altibajos. Como se observa en el gráfico 1, las diferencias entre los medios nacionales y locales son muy pronunciadas y existe una gran asimetría en el uso de los vínculos.

En los últimos años se refleja un crecimiento muy elevado del hipertexto provocado por la introducción de las etiquetas semánticas. Es un proceso que se ha dado en los diarios desde 2010 hasta 2014, según las cabeceras, pero que explica los picos y la progresión acelerada en el último período.

En los últimos años se ha producido un crecimiento muy pronunciado motivado por la introducción de las etiquetas semánticas, el tipo de hipervínculo predopor su crecimiento exponencial a partir de 2012 a consecuencia del rediseño realizado en febrero de ese mismo año y que incorporó la exploración semántica de contenidos mediante tags o etiquetas. minante en cinco de los seis periódicos analizados 


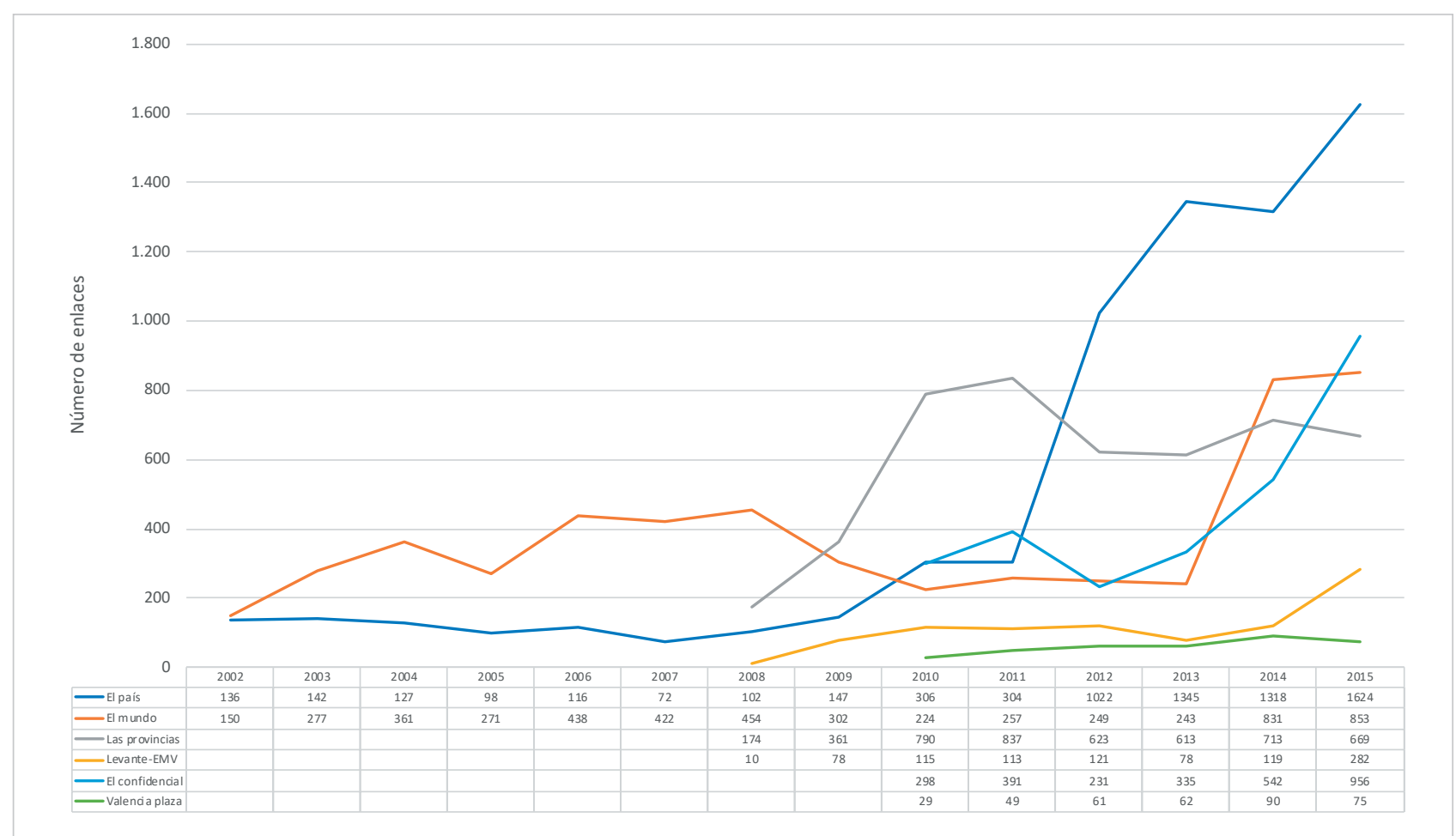

Gráfico 1. Número de enlaces semánticos por medios. Evolución cronológica 2002-2015

\section{Tipos de enlaces semánticos por medios $^{1}$}

\subsection{El país y El mundo}

El análisis detallado de los tres tipos de enlaces semánticos que aparecen en la prensa muestra, para el caso del diario El país, que el uso del hipertexto ha ido aumentando y afianzándose con los años. Como hemos avanzado anteriormente, el crecimiento exponencial se produjo en 2012 con la introducción de las etiquetas (Rubio-Lacoba, 2012), que originan que la mitad de los enlaces semánticos que se incluyen en las informaciones de portada correspondan a este tipo. Los vínculos a contenidos relacionados se han mantenido en niveles constantes en el transcurso del tiempo, con un ligero repunte a partir de 2013. En el total acumulado del período analizado (2002-2016) representan el segundo tipo de enlace más utilizado, a pesar de que desde 2010 los incluidos en el interior del cuerpo de las informaciones se han incrementado progresivamente y a día de hoy ya han superado a los contenidos relacionados. Este mayor uso de los enlaces en el relato está provocado

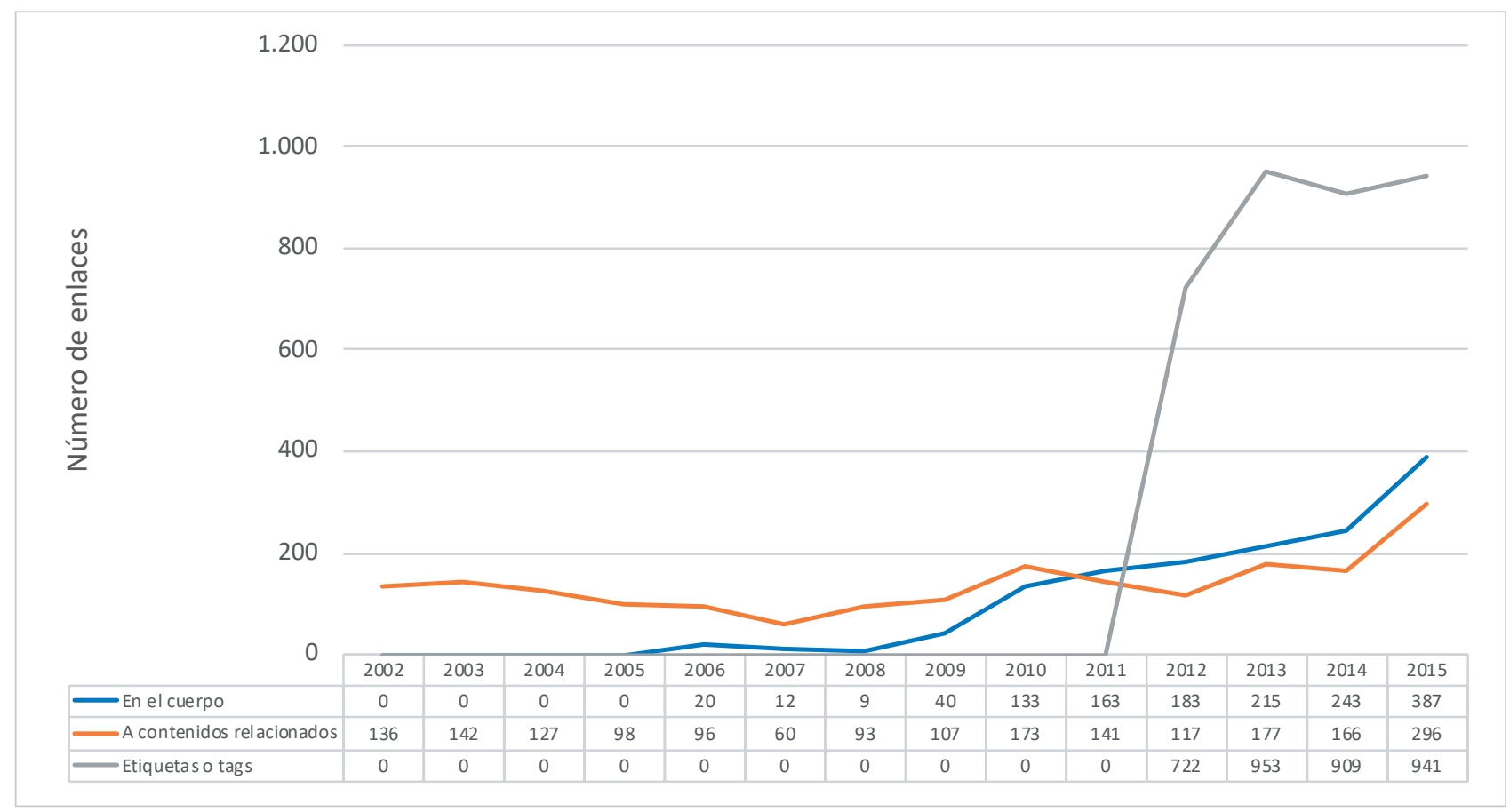

Gráfico 2. El país: tipos de enlaces (2002-2015) 
por la llegada de las tags. Una parte de los enlaces incluidos en el cuerpo de la información remiten en la última época a los mismos repositorios que el lector localiza si recurre a las etiquetas semánticas.

Una precisión: a la hora de contabilizar el número de enlaces semánticos de El país se han obviado las etiquetas desde 2002 hasta febrero de 2012 para no falsear la realidad histórica original. Por el trabajo de Rubio-Lacoba (2012) se sabe que las noticias de la hemeroteca dispusieron de etiquetas semánticas que fueron migradas retrospectivamente en 2012 -a pesar de que no se incluían en la publicación original-. Por ello se han tenido en cuenta sólo desde el momento en que ciertamente se incorporaron a la rutina periodística del diario.

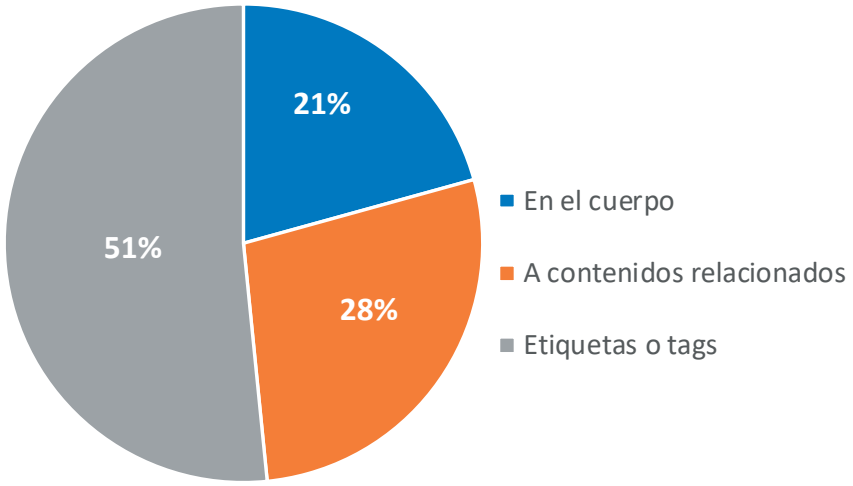

Gráfico 3. El país: porcentajes de los tipos de enlace (2002-2016)

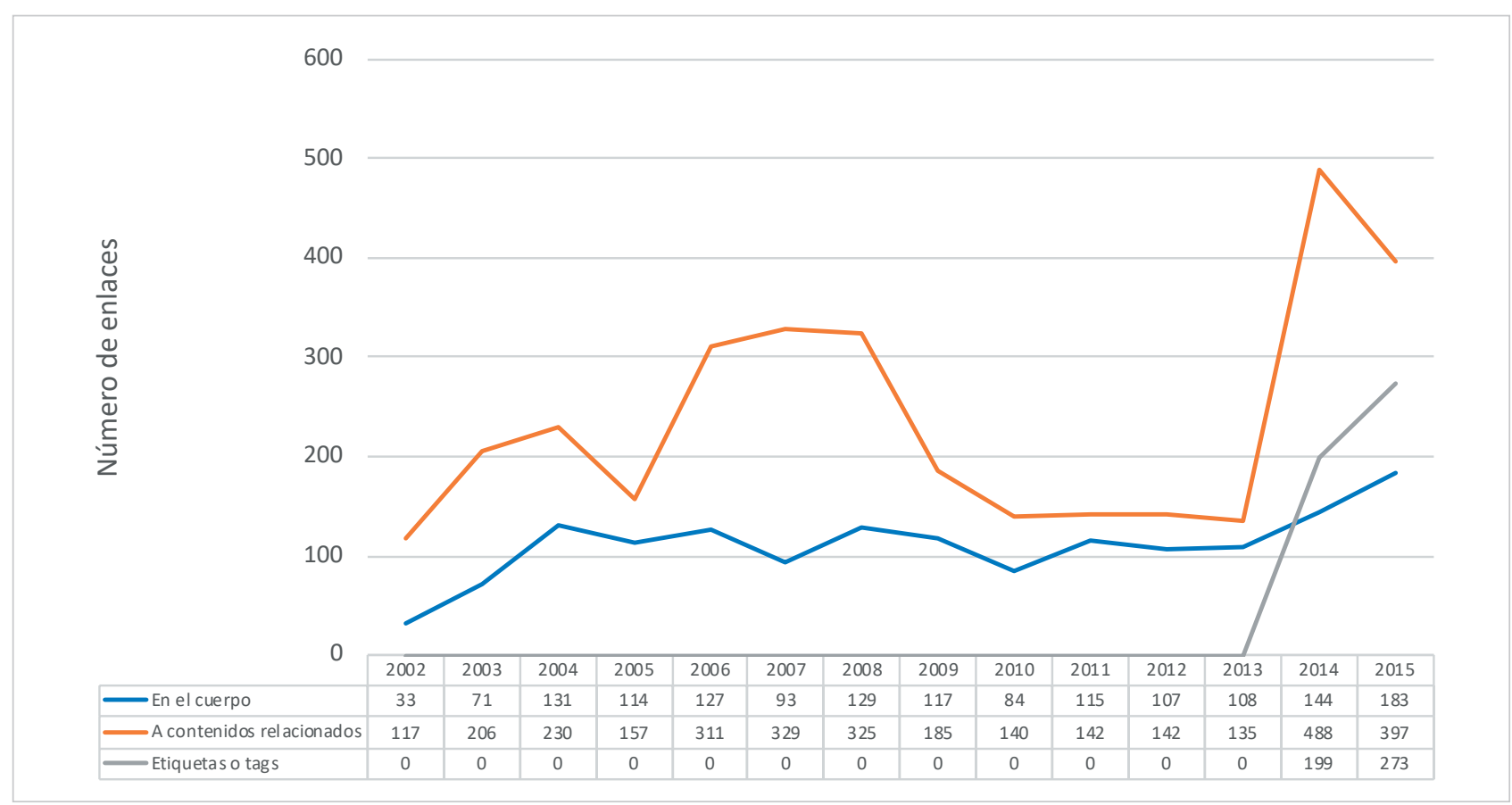

Gráfico 4. El mundo: tipos de enlaces (2002-2015)

En El mundo, el uso del hipertexto se ha fortalecido con el paso del tiempo, a pesar de que el crecimiento no ha sido constante, sino que ha tenido auges y declives abruptos. El tipo de enlace semántico más empleado es el de los contenidos relacionados. En el total histórico acumulado, 6 de cada 10 vínculos que incluye este periódico en sus informaciones pertenecen a la categoría de informaciones sugeridas.

Los vínculos en el cuerpo de la información han estado siempre presentes, con un incremento en los primeros años (20022005), un estancamiento durante una década, y un crecimiento destacado en los dos

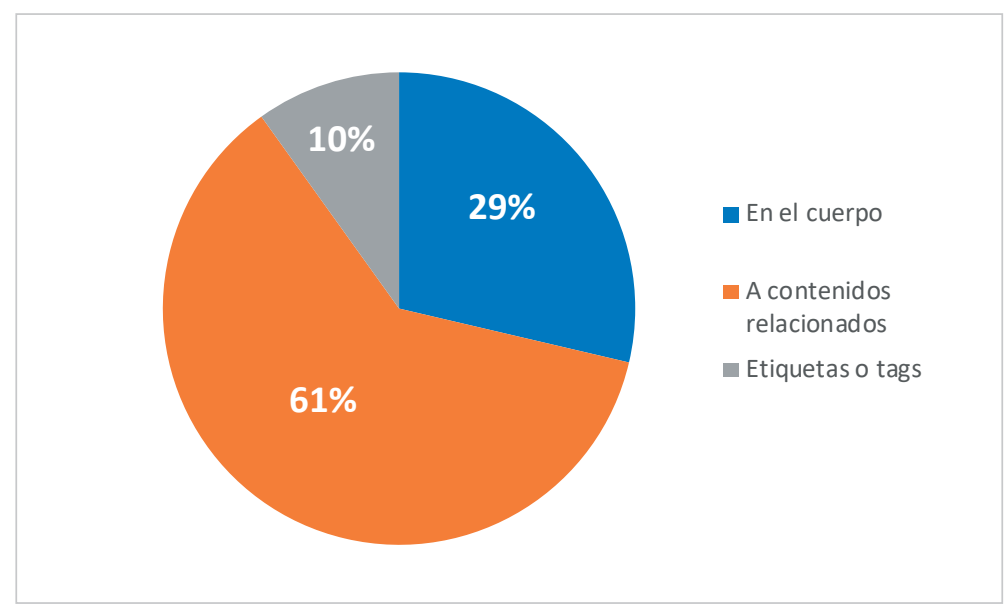

Gráfico 5. El mundo: porcentajes de los tipos de enlace (2002-2016) últimos años, coincidiendo con la introducción de las etiquetas semánticas. El mundo ha sido uno de los diarios que más ha retrasado la integración de tags. 


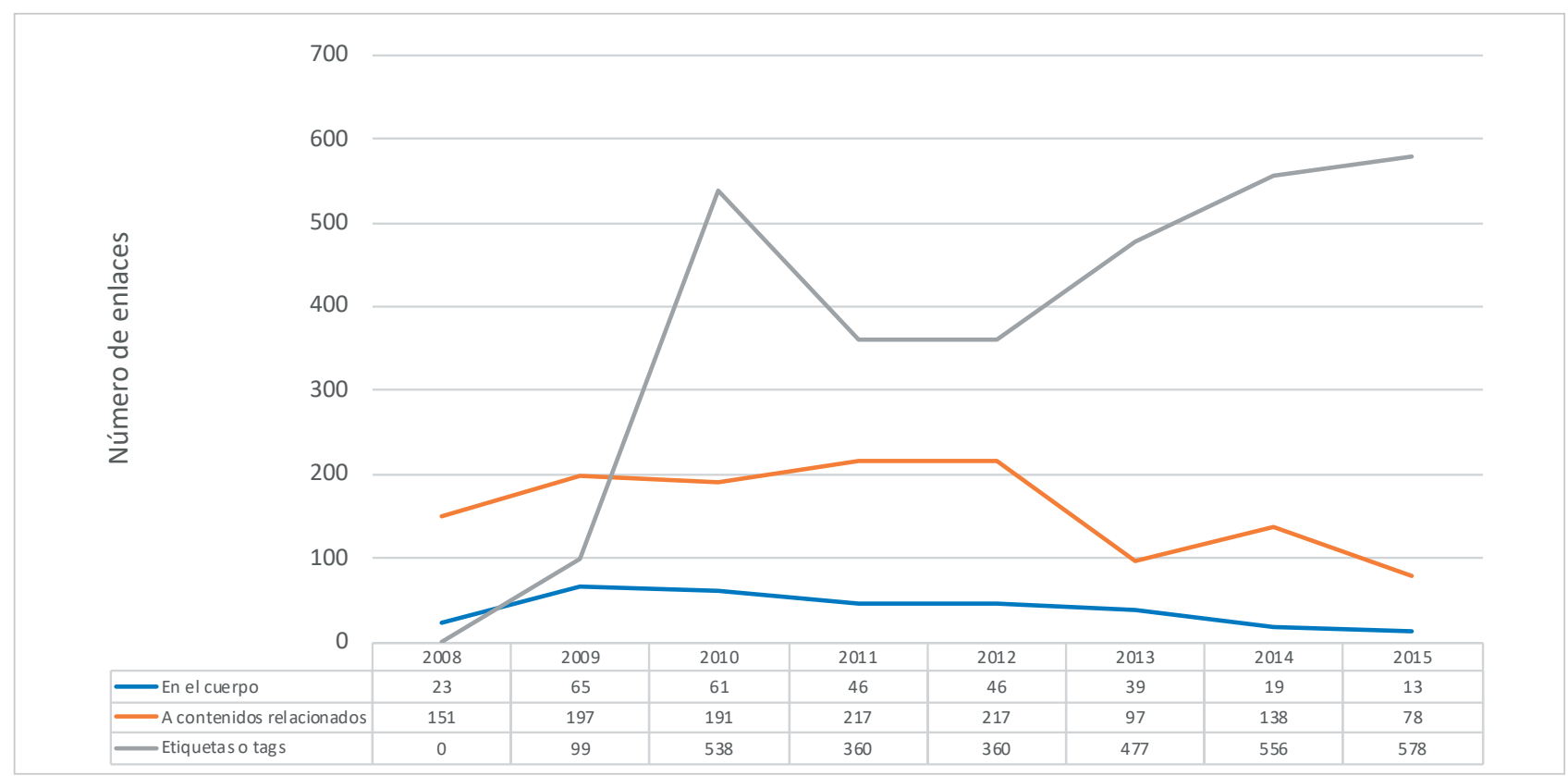

Gráfico 6. Las provincias: tipos de enlaces (2008-2015)

\subsection{Las provincias y Levante-EMV}

Aunque el periódico Las provincias muestra unos valores muy altos en el total de enlaces semánticos y más próximos a las cifras de los medios nacionales que a las de los diarios locales, el uso de la hipertextualidad se ha reducido con el paso de los años, tanto en los vínculos del relato informativo como en los contenidos relacionados.

Este número global tan elevado se explica por el uso de las etiquetas. El diario del grupo Vocento fue el pionero de los medios analizados en incluir este recurso, y lo hizo en dos fases y mediante dos categorías:

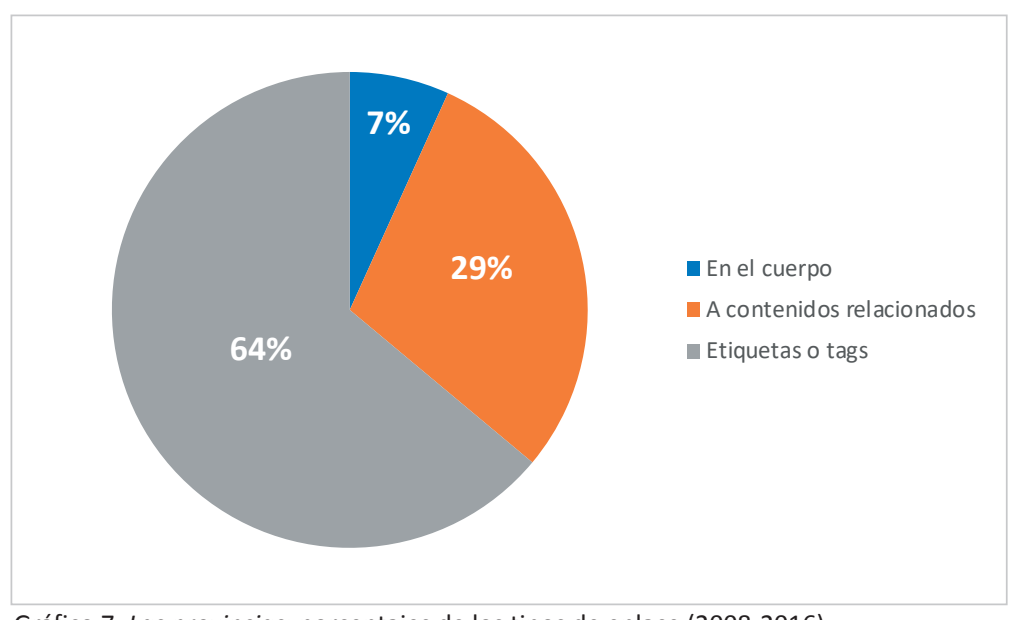

Gráfico 7. Las provincias: porcentajes de los tipos de enlace (2008-2016)

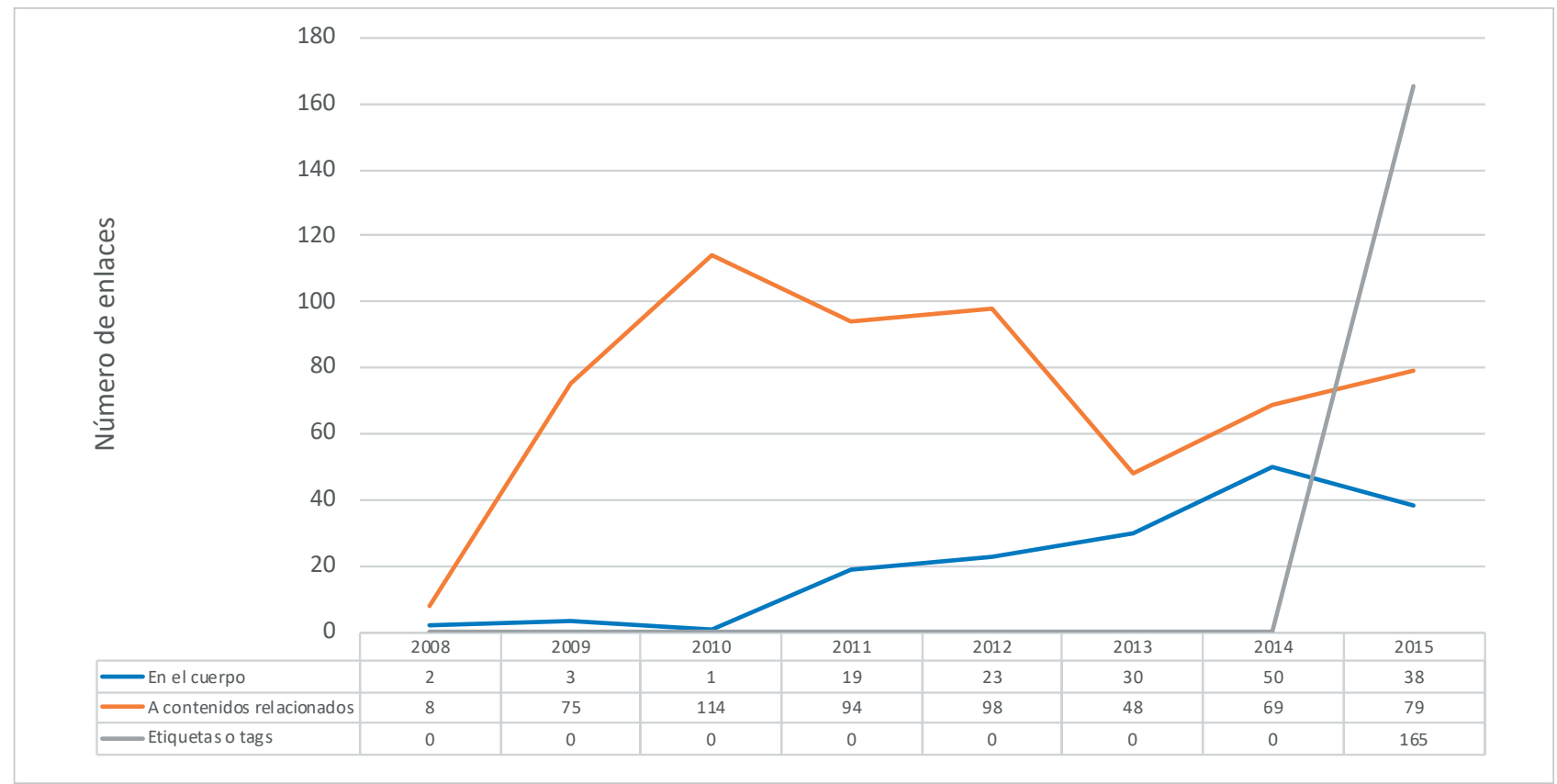

Gráfico 8. Levante-EMV: tipos de enlaces (2008-2015) 
- en 2009 integró lo que denomina tags, que son términos extraídos automáticamente por el CMS del titular de la información, prescindiendo de las palabras vacías. Cuando se clica en uno de esos vocablos, el enlace envía al buscador interno de la publicación que automáticamente ha incluido en el cajetín de búsqueda el término seleccionado;

- en 2014, Las provincias añadió una segunda modalidad de etiquetas con el nombre de "temas" y que corresponden a lo que en otros medios -y en este trabajo- se identifica como tags. Es decir, las palabras que indizan el contenido de las informaciones y remiten a repositorios temáticos que almacenan las informaciones cronológicamente.

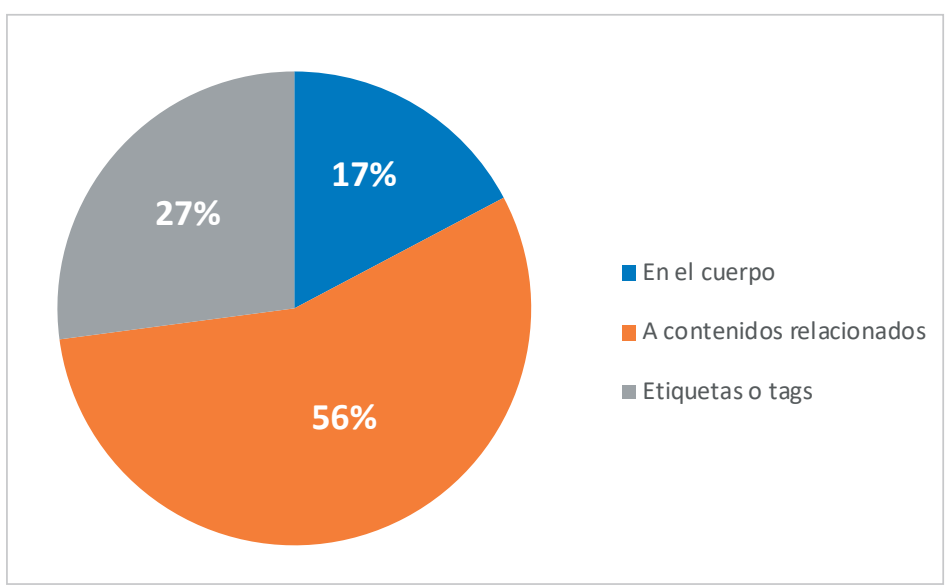

Gráfico 9. Levante-EMV: porcentajes de los tipos de enlace (2008-2016)

El diario Levante-EMV, del grupo Prensa Ibérica, ha intensificado notablemente el uso de los enlaces en todas sus modalidades, ya que en los primeros años de la publicación digital el empleo del hipertexto era un recurso inexistente. Los enlaces a contenidos relacionados (con el 56\%) es el tipo de enlace semántico que más ha sido utilizado hasta la incorporación en 2015 de las etiquetas. Los vínculos en el cuerpo de la información representan sólo el 17\% del global tras un crecimiento sostenido que se ha reducido ligeramente en el último año.

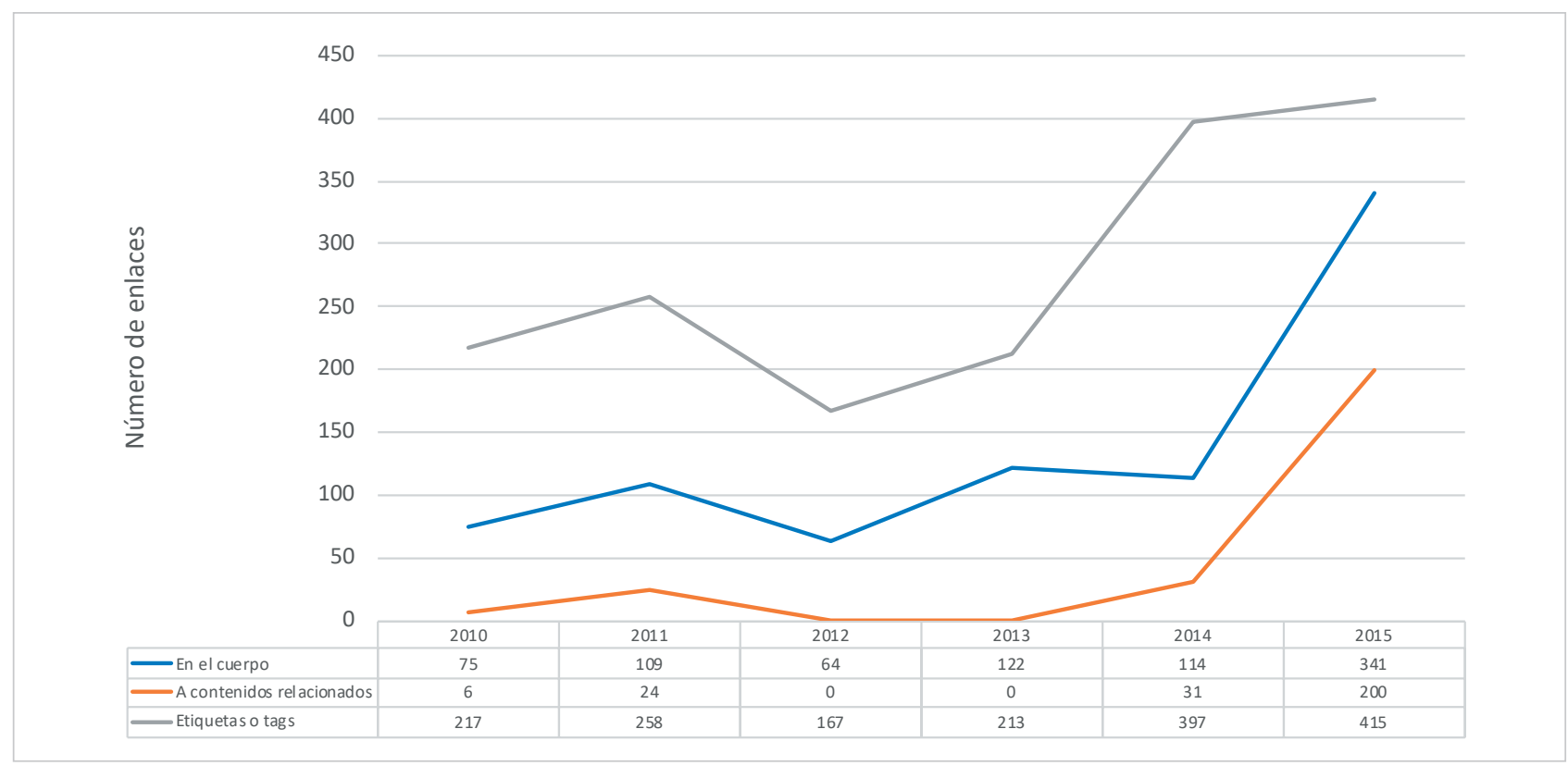

Gráfico 10. El confidencial: tipos de enlaces (2010-2015)

\subsection{El confidencial y Valencia plaza}

Toda la tipología de enlaces semánticos está presente en El confidencial desde el inicio del análisis en 2010. Tras una caída global del hipertexto en 2012, su evolución se ha vuelto vertiginosa a partir de 2014. Las etiquetas es la modalidad predominante y le siguen, a cierta distancia, los vínculos en el cuerpo de las informaciones, que representan algo menos de un tercio del total acumulado en el período 2010-2015.

En Valencia plaza el hipertexto también es un recurso asentado, especialmente desde 2013. En 2011 los enlaces situados en el cuerpo de las informaciones y los contenidos relacionados

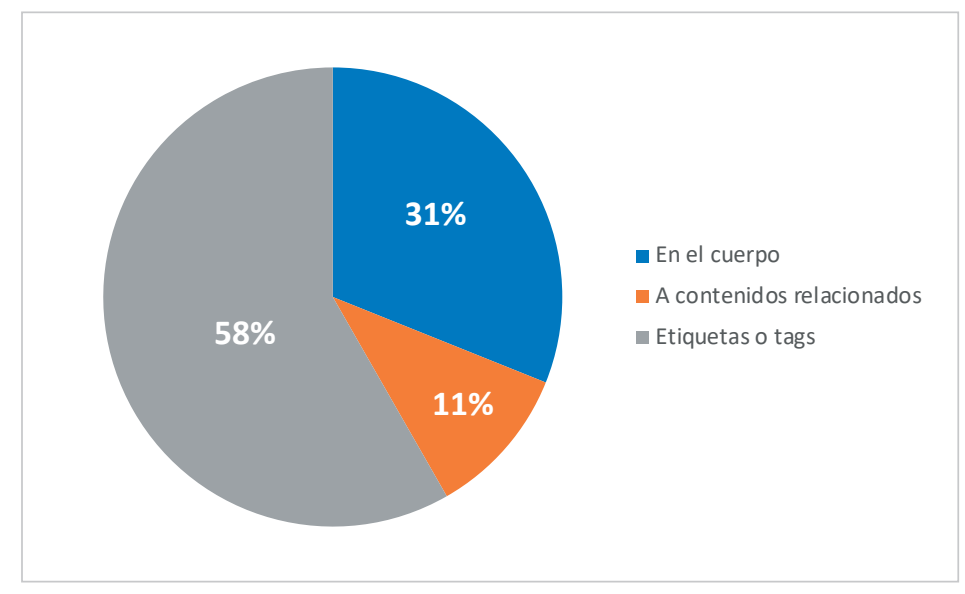

Gráfico 11. El confidencial: porcentajes de los tipos de enlace (2010-2016) 


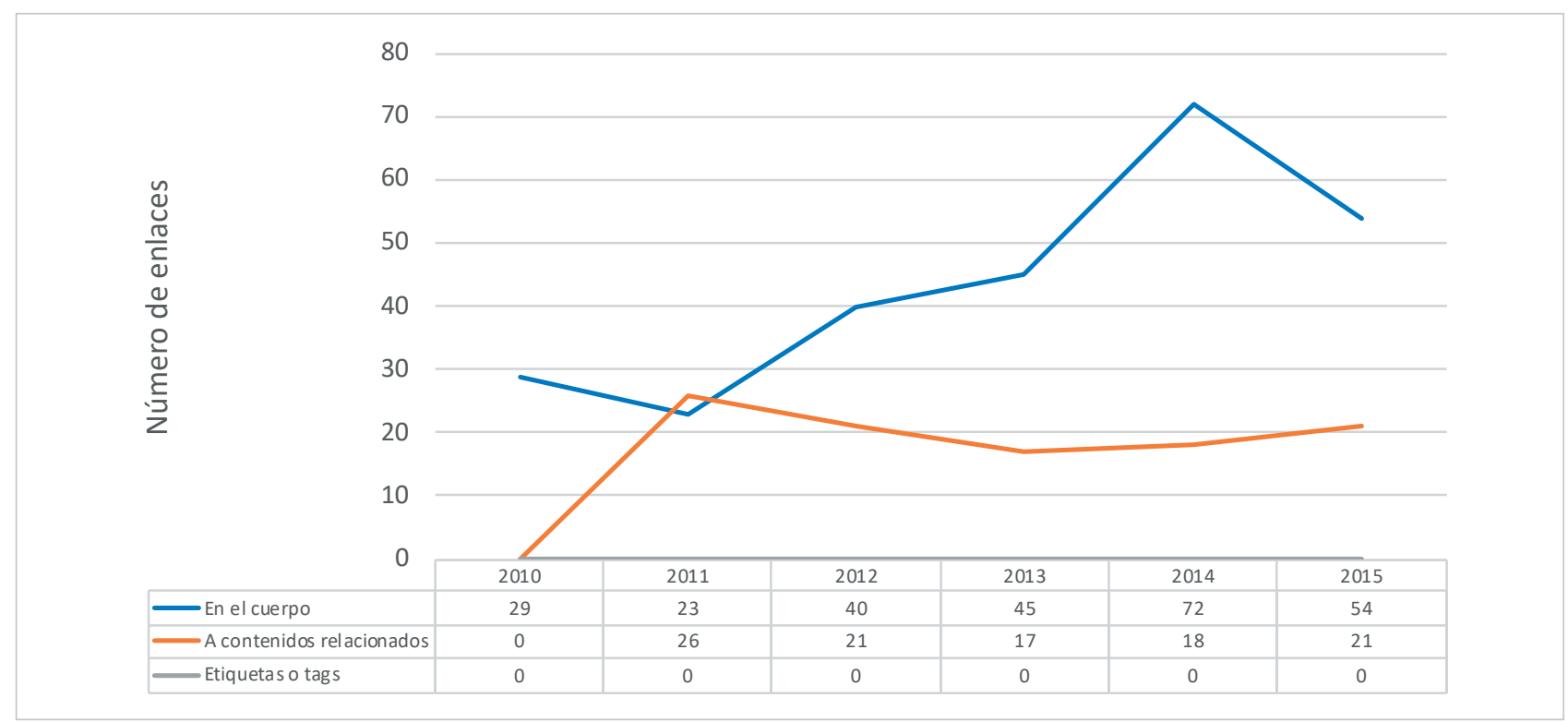

Gráfico 12. Valencia plaza: tipos de enlaces (2010-2015)

tenían cifras prácticamente idénticas. No obstante, a partir de esa fecha los primeros han crecido notablemente ${ }^{2}$, mientras que los segundos se han estancado. Conviene señalar que en el global acumulado, es mayoritario el uso de enlaces en el relato informativo y tres de cada cuatro vínculos que aparecen en las noticias pertenecen a este tipo.

Las etiquetas no aparecen en el estudio porque se incorporaron en el segundo semestre de 2015, momento que ya no recoge este trabajo por la desaparición de la hemeroteca del diario, elemento imprescindible para la selección de las unidades de muestra de esta investigación.

\section{Enlaces internos y externos}

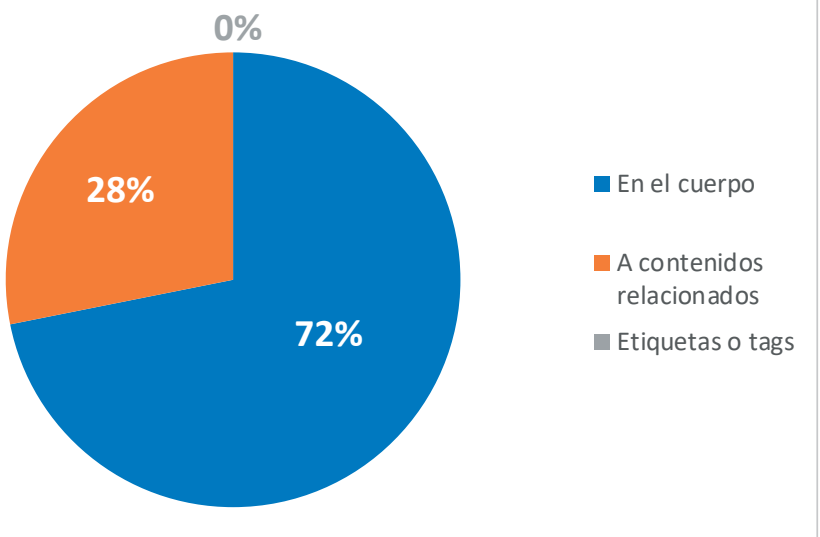

Los resultados vistos del uso del hipertexto en las cabeceras analizadas demuestran que el período de madurez de este recurso ha llegado entre 2010 y 2015. Por ello los datos que interesan sobre el destino de los enlaces son los de esta etapa de consolidación.

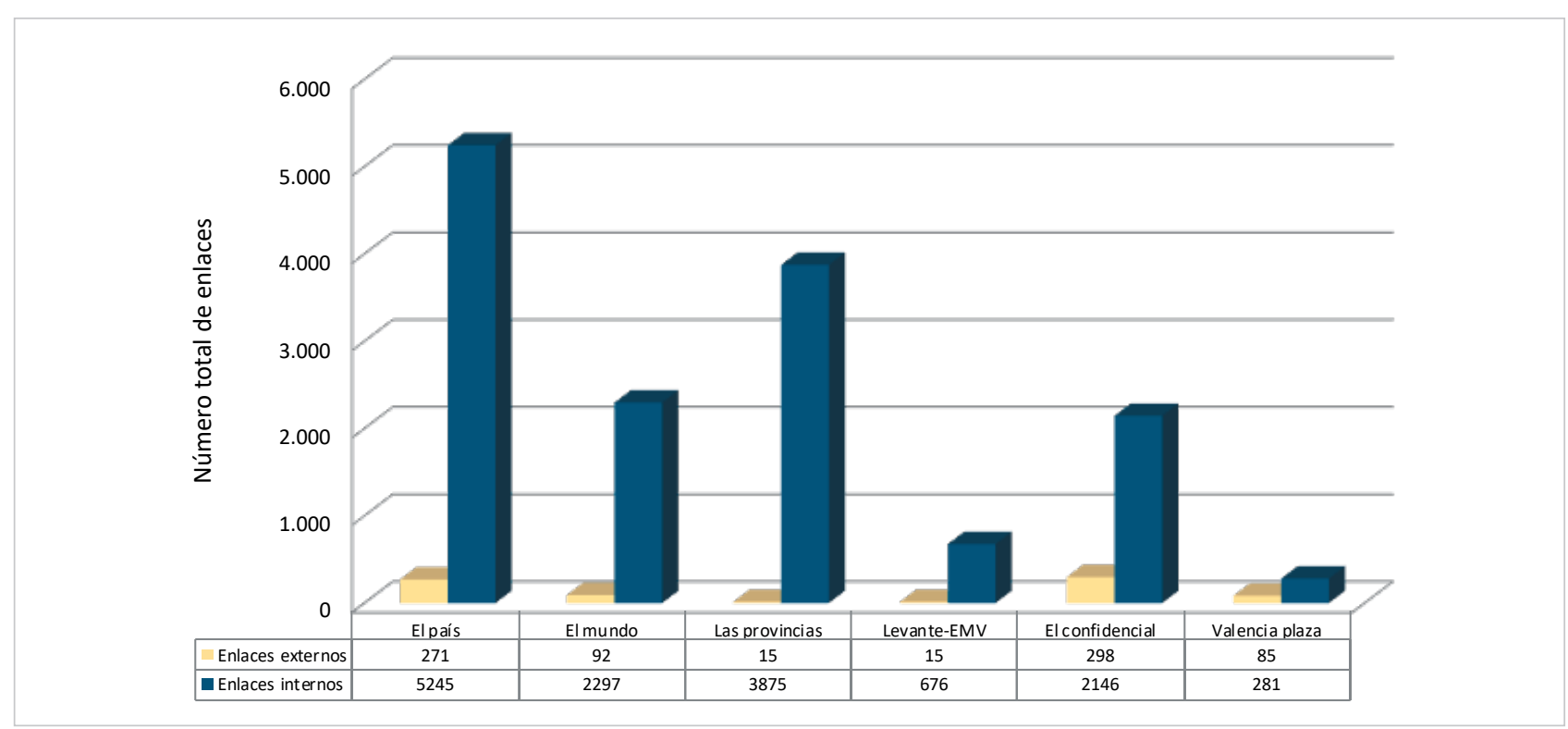

Gráfico 14. Número total de enlaces internos y externos (2010-2015) 
Es insignificante el número de vínculos externos que se incorporan a las noticias con respecto a los internos; todos los medios practican una estrategia informativa autorreferencial. Únicamente los dos nativos digitales presentan un mayor número de nodos a destinos ajenos, mientras que en los diarios con tradición y publicación en papel los vínculos a fuentes externas son prácticamente inexistentes.

El intento de que el lector permanezca el mayor tiempo posible dentro de la publicación navegando entre páginas propias y de que no se marche a recursos externos, explica esta política restrictiva de destino y que no aprovecha una de las ventajas inherentes de internet en el periodismo digital: proporcionar al lector una documentación rica y sin límites.

El intento de que el lector permanezca el mayor tiempo posible dentro de la publicación explica el empleo desmesurado de los enlaces internos, tanto en el total de los hipervínculos semánticos como en los incluidos específicamente en el relato informativo

\section{Enlaces semánticos en el cuerpo de las piezas informativas}

La cantidad de enlaces semánticos incluidos en el relato informativo es muy superior en los medios de ámbito nacional con respecto a los diarios locales, que usan en menor número este recurso. El país y El confidencial tienen una evolución ascendente en el tiempo y acusada en 2015. Por el contrario los valores de El mundo están estancados desde hace una década.

Respecto a los medios locales, Las provincias y Levante han invertido sus trayectorias con el paso de los años, mientras que en Valencia plaza el empleo de este tipo de vínculos no ha sufrido variaciones desde 2010 a 2014, aunque se estima un repunte en 2015 dado que los datos consignados sólo recogen el primer semestre de ese año.

Respecto a la evolución cronológica, el $95 \%$ de las noticias que publica El país en su portada contiene algún enlace en el cuerpo de la información. El desarrollo del hipertexto ha sido progresivo en la última década y abrupto en los dos últimos años. Estas cifras demuestran la consolidación y madurez del fenómeno. En El mundo la cantidad de vínculos incluidos en el texto periodístico ha aumentado respecto a hace quince años del 31 al 53\% y en fechas recientes la mitad de las informaciones publicadas en la portada de la web disponen de al menos un enlace. Sin embargo, la práctica ha sido irregular en el tiempo e incluso ha descendido con respecto a lo que ocurría hace una década.

La hipertextualidad semántica se ha incrementado y consolidado en las noticias de portada de todos los diarios españoles estudiados

El diario El confidencial, junto a El país, es el que mayor uso del hipertexto realiza en el interior del relato informativo. En el primer lustro las cifras permanecieron estables, pero es a partir de 2015 cuando la intensidad resulta notable. Actualmente casi 9 de cada 10 informaciones publicadas en portada cuentan con algún enlace en el cuerpo de la noticia.

En los medios valencianos, los valores en Las provincias se han mantenido estancados en los últimos nueve años y no se ha producido una mayor explotación del hipertexto. Sólo una de cada cuatro noticias publicadas en la portada dispone de al menos un enlace en el texto informativo. Tal y como hemos visto en los gráficos anteriores, de 2012 a 2015 se produjo un declive que se ha subsanado en 2016 y que ha permitido retomar la media de la publicación. En Levante-EMV el

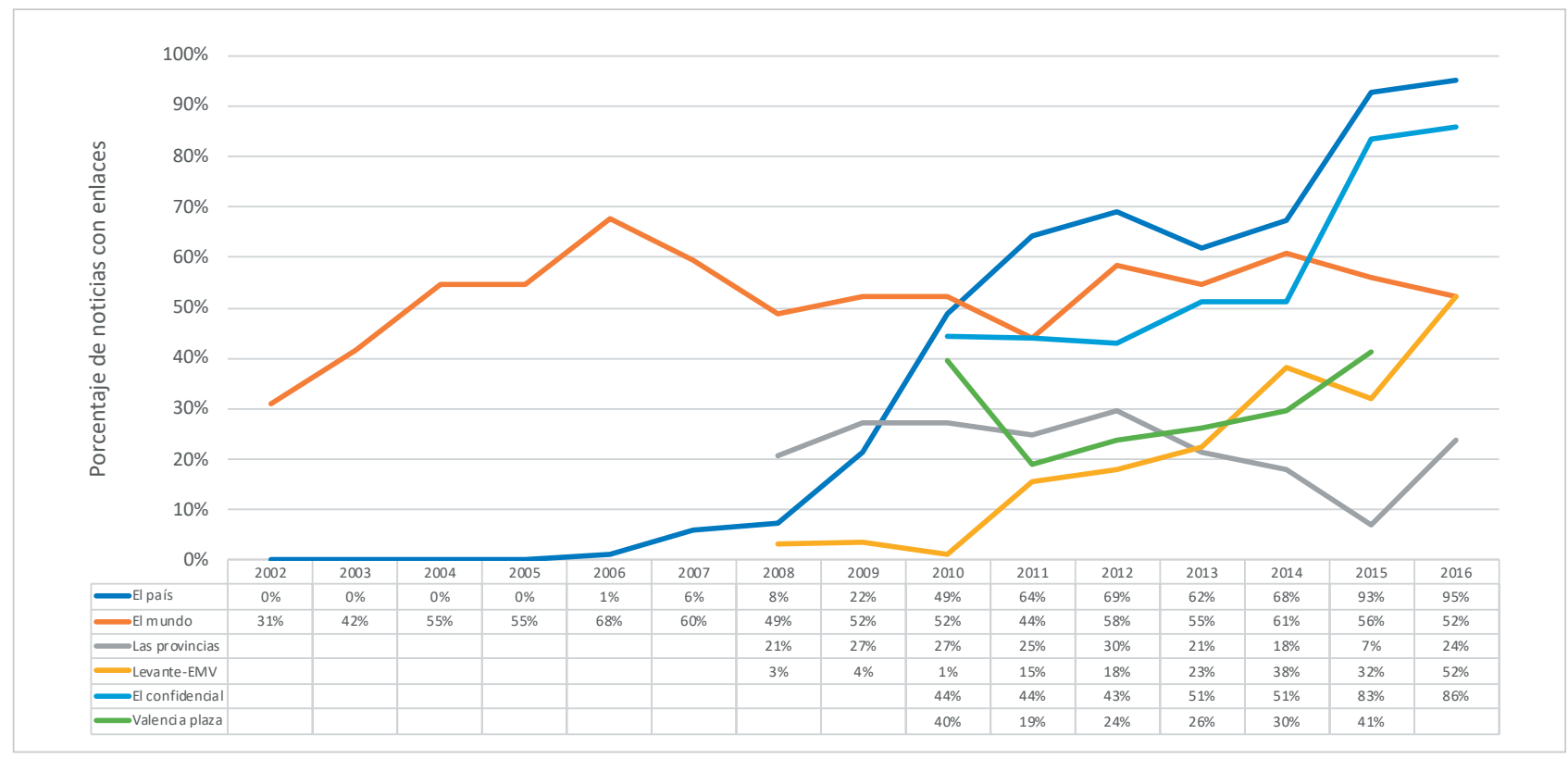

Gráfico 15. Porcentaje de piezas con enlaces en el cuerpo de la información (2002-2015) 
empleo de los vínculos en el cuerpo de la información ha tenido un despegue muy tardío, aunque desde 2011 ha crecido constante y progresivamente. En 2016 sólo la mitad de las informaciones de portada contienen algún enlace. Finalmente, en el caso de Valencia plaza el porcentaje de noticias con vínculos en el relato informativo se ha mantenido estable en los últimos años y no hay variaciones significativas.

\section{Anticipación del nodo de destino en los enlaces del cuerpo de la información}

A pesar de que el texto libre es la opción exclusiva en la morfología del anclaje y, por tanto, no hay limitaciones para sugerir con eficacia el contenido del nodo de destino, resultan llamativos los datos que se obtienen sobre la anticipación.

Se detectan abundantes deficiencias en la anticipación del contenido del nodo de destino en la mayoría de los anclajes y en todos los diarios. Las provincias, El país y Levante-EMV son los medios que peor la resuelven y la mitad de los términos elegidos para anclar impiden al lector prever el lugar al que les enviará ese vínculo. Los porcentajes son muy elevados y demuestran deficiencias en la narrativa e ineficacia a la hora de invitar al lector a clicar en él. El mundo y los dos nativos digitales son los que hacen un manejo más eficiente con cifras entre el 60 y $70 \%$ de anticipación clara del contenido, aunque la falta de comprensión sigue siendo alta. También es llamativo que el medio que mejor avanza el destino sea el más pequeño y joven: Valencia plaza, con un $73 \%$ de anclajes que preludian perfectamente el contenido que le será mostrado al lector.

Los nombres propios de personas representan una cantidad limitada de anclajes, pero son un buen ejemplo para demostrar el problema de la anticipación, que sigue sin resolverse después de dos décadas de hipertextualidad.

En esta investigación se constata que un nombre propio puede remitir a múltiples nodos: un perfil biográfico publicado en el propio medio, una ficha con el currículo profesional en la web de la empresa para la que trabaja, su blog o web personal, cualquier noticia en la que resultó protagonista, un repositorio con todas las noticias en las que aparece, e incluso, en el caso de escritores o colaboradores de medios, un repositorio de los artículos publicados como autor en ese diario.

\section{Tipos del nodo de destino de los enlaces del cuerpo de la información}

Si excluimos al propio diario como destino mayoritario de los enlaces, las webs institucionales y otros medios de comunicación son las fuentes más frecuentes a las que remiten los vínculos. El resto de destinos: blogs, redes sociales, webs personales u otro tipo de recursos tienen valores prácticamente nulos.

Los periódicos se comportan de manera similar según las parejas que hemos establecido para las comparativas y que tienen períodos de análisis idénticos.
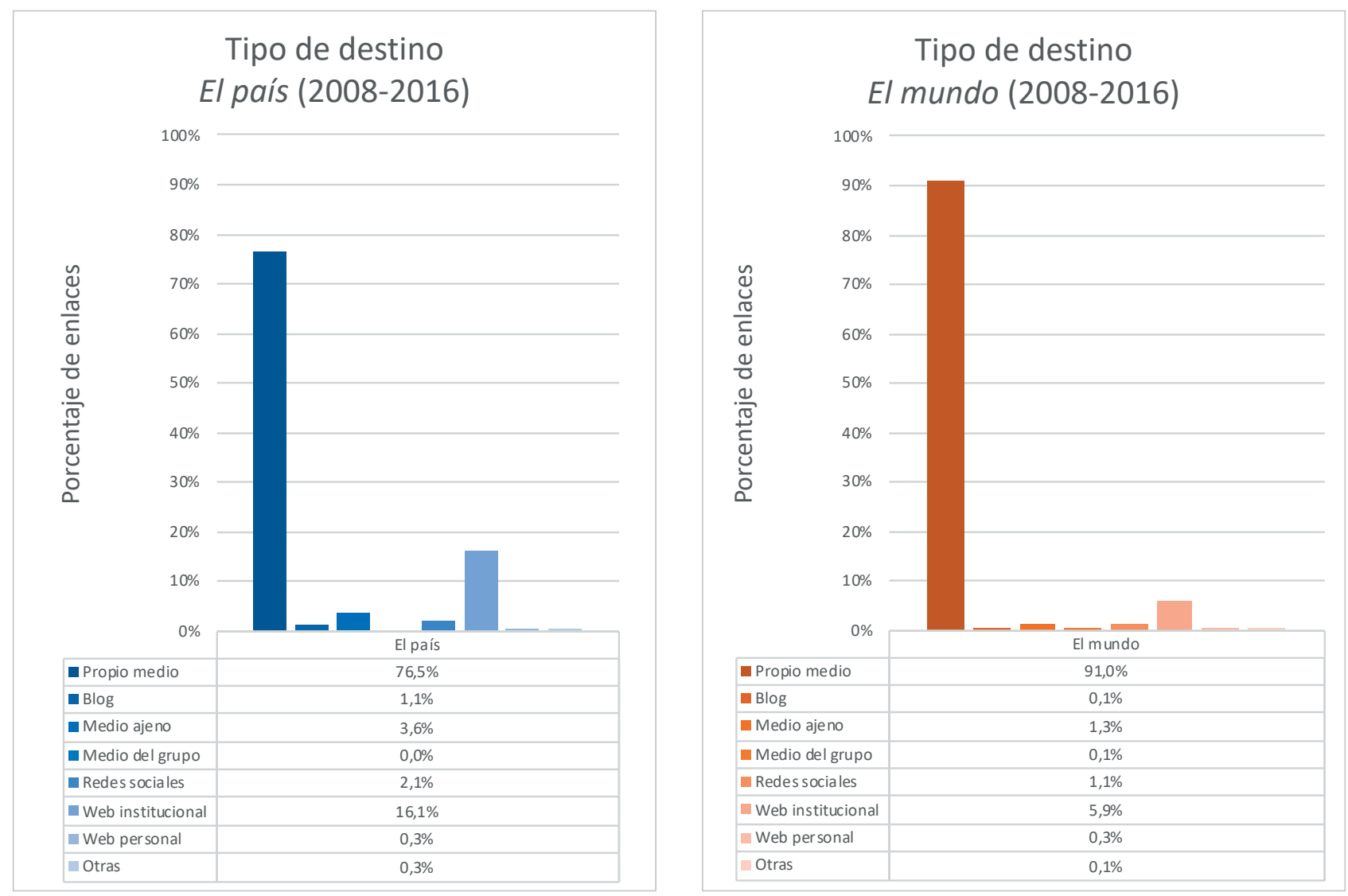

Gráfico 16a. Porcentajes de los tipos de destino de los enlaces incluidos en el relato informativo 

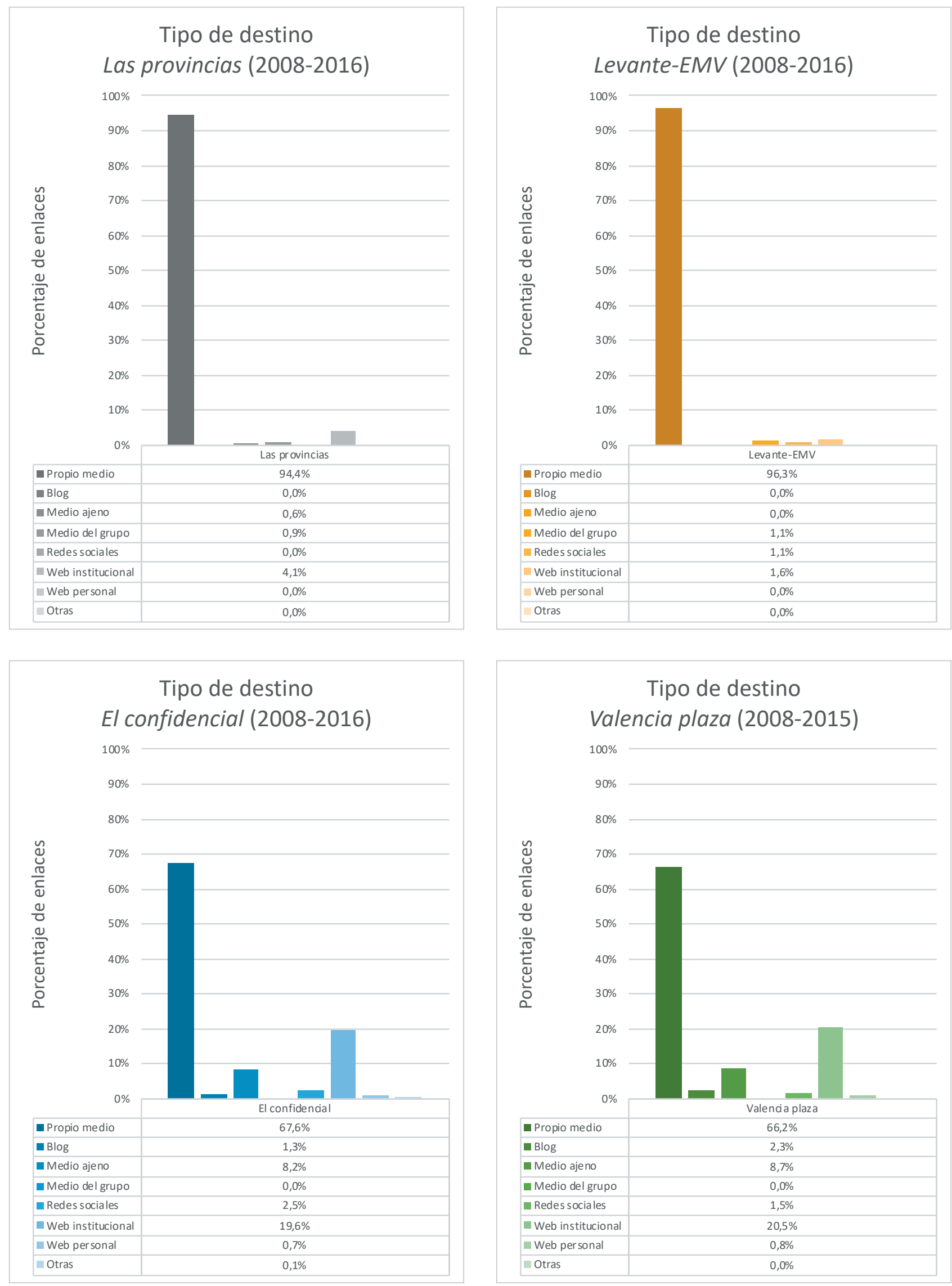

Gráfico 16b. Porcentajes de los tipos de destino de los enlaces incluidos en el relato informativo 
El país y El mundo recurren como segunda fuente de destino a las webs institucionales y resulta destacado que no utilizan recursos de medios de su mismo grupo de comunicación, aunque sean mayoritariamente medios audiovisuales. Las provincias y Levante-EMV sí que hacen mayor uso del resto de cabeceras que pertenecen a sus grupos de prensa. Finalmente, en El confidencial y Valencia plaza los destinos externos más frecuentados son las webs institucionales y los medios de comunicación ajenos.

\section{Conclusiones}

La hipertextualidad semántica se ha incrementado y consolidado en las noticias de portada de todos los diarios españoles estudiados. Hay un crecimiento y una progresión cuantitativa en las cabeceras desde el inicio del período de análisis hasta la actualidad, aunque el desarrollo se ha producido con vicisitudes. Aun así, es indiscutible el empleo cada vez más frecuente de los hipervínculos y la diversidad tipológica que adoptan.

El primer estudio empírico realizado en la prensa española (Pérez-Marco, 2004) detectaba una única modalidad de vínculos semánticos, la de los contenidos relacionados. Ahora son tres los tipos de enlaces los que se utilizan cotidianamente en la creación de las informaciones:

- insertados en el relato periodístico;

- noticias recomendadas;

- etiquetas o tags.

Hay diferencias cuantitativas acusadas entre los medios nacionales y locales, hecho que demuestra que el número global de enlaces está ligado a los recursos humanos, económicos y tecnológicos de las cabeceras.

En los últimos años se ha producido un crecimiento muy pronunciado motivado por la introducción de las etiquetas semánticas, que son el tipo de hipervínculo predominante en cinco de los seis periódicos analizados. La integración de las etiquetas es un proceso semiautomatizado que no implica una indización rigurosa y con consistencia documental basada en vocabularios controlados o tesauros, sino que son términos literales extraídos por el gestor de contenidos (CMS) del texto de la noticia, que los periodistas validan, rechazan o sustituyen por otros que consideran más pertinentes.

Los enlaces que se incluyen en el relato informativo, los más complejos en su concepción y ejecución, son el tipo menos presente en los medios, aunque también se descubre disparidad dependiendo del ámbito de edición del diario, si bien los nativos digitales los utilizan en una proporción más elevada que aquellos con tradición en papel. Su uso ha aumentado con el paso de los años en la totalidad de las cabeceras, pese a que el crecimiento último se debe a la aparición de los repositorios temáticos, los sitios que archivan informaciones publicadas referidas a personas, acontecimientos $u$ organizaciones y que se originan gracias al etiquetado semántico de las noticias.

El crecimiento de esa modalidad de hipervínculo en el interior del relato no proviene de la tarea crítica de evaluación de las noticias publicadas con anterioridad o de los recursos de internet que pueden resultar más pertinentes para el lector justo en ese instante de la narración periodística, sino que remiten a un repositorio, al que a su vez ya están redirigiendo las mismas etiquetas semánticas

Aunque el desarrollo se ha producido con vicisitudes, se comprueba el empleo cada vez más frecuente de los hipervínculos y la diversidad tipológica que adoptan

que incorpora la pieza. Esta práctica, sobre todo en temas o personalidades destacadas o recurrentes en la actualidad, no contribuye a ofrecer información precisa y conocimiento en la lectura de la noticia, sino que más bien causa dispersión, fragmentación y vaguedad en la navegación, mucho más si tenemos en cuenta que estos "almacenes de noticias" tienen una organización basada únicamente en criterios cronológicos y no permiten ningún filtro de búsqueda o presentación de resultados. Paradójicamente, con este uso los hipervínculos del cuerpo no cumplen con la misión periodística de orientar, explicar y ofrecer profundidad, sino que potencian una sobreinformación fragmentada.

Se detectan deficiencias en la anticipación del contenido del nodo de destino en la mayoría de los anclajes, lo que impide al lector prever el lugar al que le enviará ese vínculo. Este hecho demuestra que la narrativa en relación con la hipertextualidad no ha alcanzado su potencial óptimo.

La búsqueda por lograr un mayor número de lectores explica el empleo desmesurado de los enlaces internos, tanto en el total de los hipervínculos semánticos como en los incluidos específicamente en el relato informativo. El uso del hipertexto está condicionado enormemente por la búsqueda de audiencia, el posicionamiento SEO y el intento de que el lector permanezca el mayor tiempo posible en la publicación. Estas cuestiones priman sobre las puramente informativas o documentales.

Este porcentaje de enlaces internos abrumador es coincidente con lo que indican las investigaciones previas y más recientes (Diezhandino-Nieto, 2008; Fondevila-Gascón; Segura-Jiménez, 2012; Fondevila-Gascón; Beriain-Bañares; 
Del-Olmo-Arriaga, 2013; Arias-Robles; García-Avilés, 2018). En cuatro de los seis medios analizados el porcentaje de vínculos que dirigen a nodos ajenos a la publicación es menor del 5\%.

Los medios siguen practicando una política autorreferencial, que si bien es cierto que pone en valor la trayectoria del diario y su fondo documental, apenas deja margen para ofrecer recursos valiosos de la red. Los medios nativos digitales analizados son los que muestran una mayor apertura hacia el exterior.

\section{Notas}

1. Para la exposición de los datos se han tenido en cuenta los condicionantes de las unidades de análisis y se ha optado por una presentación mediante valores absolutos que permite describir y percibir la evolución del hipertexto en la prensa española para dar respuesta al objetivo principal de esta investigación descriptivo-retrospectiva. La homogeneización de datos necesaria para realizar comparativas se ha conseguido utilizando porcentajes y no medias, ya que la desviación estándar entre las unidades de análisis es muy alta y no permite llegar a conclusiones científicamente válidas.

Los resultados se exponen por años, y no trimestralmente, para examinar con más facilidad las tendencias de un período que abarca hasta quince años.

2. Como ya señalamos anteriormente, las cifras de recogidas en 2015 para Valencia plaza sólo muestran el primer semestre, de ahí que se observe una cierta caída que no es real.

\section{Referencias}

Arias-Robles, Félix (2015). El hipertexto periodístico. Influencia del enlace en el mensaje, el emisor y el receptor de información. Tesis doctoral. Universidad Miguel Hernández de Elche.

http://dspace.umh.es/handle/11000/1924

Arias-Robles, Félix (2016). "Teoría y práctica del lenguaje ciberperiodístico. SEO, redes e (hiper)textos". Revista mediterránea de comunicación, v. 7, n. 2, pp. 177-194.

https://doi.org/10.14198/MEDCOM2016.7.2.8

Arias-Robles, Félix; García-Avilés, José-Alberto (2017). “¿Un futuro sin enlaces? La mutación del hipertexto en las nuevas pantallas". Hipertext.net, n. 15, pp. 28-35.

https://doi.org/10.2436/20.8050.01.43

Arias-Robles, Félix; García-Avilés, José-Alberto (2018). “El destino del enlace periodístico: percepción de los editores y aplicación práctica de la hipertextualidad en los medios españoles”. Palabra clave, v. 21, n. 2, pp. 275-309.

https://doi.org/10.5294/pacla.2018.21.2.2

Armañanzas, Emy; Díaz-Noci, Javier; Meso, Koldo (1996). El periodismo electrónico. Barcelona: Ariel. ISBN: 97884 34412705

Armentia-Vizuete, José-Ignacio; Elexgaray-Arias, Jon-Imanol; Pérez-Fuentes, Juan-Carlos (1999). Diseño y periodismo electrónico. Bilbao: Servicio Editorial de la Universidad del País Vasco. ISBN: 9788483731291

Arrese-Reca, Ángel (2016). “Retroperiodismo”. En: Rodríguez-Rodríguez, José-Miguel (coord.). Retroperiodismo, o el retorno a los principios de la profesión periodística. Madrid: SEP, pp. 15-28. ISBN: 9788494494123

Barbosa, Suzana; Mielniczuk, Luciana (2011). "Ferramenta para análise de hipertextualidade em cibermeios”. En: Palacios, Marcos. Ferramentas para análise de qualidade no ciberjornalismo (vol. 1: Modelos), pp. 37-50. Covilhã: LabCom Books.

http://www.labcom-ifp.ubi.pt/livro/82

Cantos-Gómez, Pascual; Martínez-Méndez, Francisco-Javier; Moya-Martínez, Gregorio (1994). Hipertexto y documentación. Murcia: Secretariado de publicaciones de la Universidad. ISBN: 8476845529

Carr, Nicholas (2011). Superficiales. ¿Qué está haciendo internet con nuestras mentes? Madrid: Taurus. ISBN: 97884 30608126

Codina, Lluís (1997). "H de hypertext, o la teoría de los hipertextos revisitada". Cuadernos de documentación multimedia, n. 6-7.

Codina, Lluís (2000). “Evaluación de recursos digitales en línea: Conceptos, indicadores y métodos". Revista española de documentación científica, v. 23, n. 1, pp. 9-44.

https://doi.org/10.3989/redc.2000.v23.i1.315

Codina, Lluís (2003). “Hiperdocumentos: Composición, estructura y evaluación”. En: Díaz-Noci, Javier; Salaverría, Ramón (eds.). Manual de redacción ciberperiodística. Barcelona: Ariel, pp. 141-194. ISBN: 8434412977

https://periodismoabc.files.wordpress.com/2012/02/hipertextos-manual-de-redaccion-ciberperiodistica.pdf 
De-Maeyer, Juliette (2011). "Methods for mapping hyperlink networks". In: International symposium of online journalism, Austin, Texas.

https://slideplayer.com/slide/8900220

De-Maeyer, Juliette (2012). "The journalistic hyperlink: Prescriptive discourses about linking in online news". Journalism practice, v. 6, n. 5-6, pp. 692-701.

https://doi.org/10.1080/17512786.2012.667273

De-Maeyer, Juliette; Holton, Avery E. (2016). "Why linking matters: A metajournalistic discourse analysis". Journalism, v. 17, n. 6, pp. 776-794.

https://doi.org/10.1177/1464884915579330

Deuze, Mark (2001). "Online journalism: Modelling the first generation of news media on the world-wide web". First Monday, v. 6, n. 10.

https://doi.org/10.5210/fm.v6i10.893

Deuze, Mark (2003). "The web and its journalisms: Considering the consequences of different types of newsmedia online". New media \& society, v. 5, n. 2, pp. 203-230.

https://doi.org/10.1177/1461444803005002004

Díaz-Noci, Javier (2001). La escritura digital: Hipertexto y construcción del discurso informativo en el periodismo electrónico. Bilbao: Universidad del País Vasco. ISBN: 8483733781

Díaz-Noci, Javier (2018). "Hipertexto en periodismo: realidad e investigaciones de futuro". Anuario ThinkEPI, v. 12, pp. 230-235.

https://doi.org/10.3145/thinkepi.2018.34

Díaz-Noci, Javier; Salaverría, Ramón (eds.) (2003). Manual de redacción ciberperiodística. Barcelona: Ariel. ISBN: 84344 12977

Diezhandino-Nieto, María-Pilar (coord.) (2008). Periodismo en la era de Internet: Claves para entender la situación actual de la información periodística en España. Barcelona: Ariel. ISBN: 9788408077565

https://bit.ly/2GvdCQb

Doherty, Skye (2014). “Hypertext and journalism: Paths for future research". Digital journalism, v. 2, n. 2, pp. $124-139$. https://doi.org/10.1080/21670811.2013.821323

Engebretsen, Martin (2006). "Shallow and static or deep and dynamic?". Nordicom review, v. 27, n. 1. https://doi.org/10.1515/nor-2017-0215

Fondevila-Gascón, Joan-Francesc (2011). "Aplicación semántica de la hipertextualidad en la prensa digital en España”. En: Verón-Lassa, José-Juan; Sabés-Turmo, Fernando (coords.). Congreso de periodismo digital. La investigación en periodismo digital: Algunos trabajos desde el ámbito universitario (12, Huesca), pp. 169-180. ISBN: 9788487175442

Fondevila-Gascón, Joan-Francesc (2014). "El uso de hipertexto, multimedia e interactividad en periodismo digital: Propuesta metodológica de ranking de calidad". Zer: Revista de estudios de comunicación, v. 19, n. 36.

http://www.ehu.eus/ojs/index.php/Zer/article/view/13488

Fondevila-Gascón, Joan-Francesc; Beriain-Bañares, Ana; Del-Olmo-Arriaga, José-Luis (2013). “Hipertexto, multimedia e interactividad: Comparativa empírica en el periodismo digital español”. En: Ziles, Klaus; Cuenca-Fontbona, Joan; Rom-Rodríguez, Josep A. (cords.). Breaking the media value chain. VII Intl conf on communication and reality. Barcelona: Universitat Ramon Llull, pp. 41-50.

https://dialnet.unirioja.es/servlet/articulo?codigo $=6367558$

Fondevila-Gascón, Joan-Francesc; Segura-Jiménez, Herlaynne (2012). “El peso de la hipertextualidad en el periodismo digital: estudio comparativo". Cuadernos de información, n. 30, pp. 31-40.

http://www.cuadernos.info/index.php/CDI/article/view/420

Karlsson, Michael; Clerwall, Christer; Örnebring, Henrik (2015). “Hyperlinking practices in Swedish online news 20072013: The rise, fall, and stagnation of hyperlinking as a journalistic tool". Information, communication \& society, v. 18 , n. 7, pp. 847-863.

Landow, George P. (1995). Hipertexto: La convergencia de la teoría crítica contemporánea y la tecnología. Barcelona: Paidós. ISBN: 9788449301865

Larrondo-Ureta, Ainara (2005). "Estructura discursiva de la noticia hipertextual: El valor de la información relacionada y documentada". Ámbitos, n. 13-14, pp. 155-175.

https://idus.us.es/xmlui/handle/11441/67822 
Larrondo-Ureta, Ainara (2009). "La metamorfosis del reportaje en el ciberperiodismo: Concepto y caracterización de un nuevo modelo narrativo". Comunicación y sociedad, v. 12, n. 2, pp. 59-88.

https://www.unav.es/fcom/communication-society/es/articulo.php?art_id=317

Larrondo-Ureta, Ainara; Díaz-Noci, Javier (2014). "Hypertextual structure of online news: A comparative research on quality media". En: Larrondo-Ureta, Ainara; Meso, Koldo; Tous, Anna (coords.). Shaping the news online. A comparative research on international quality, pp. 249-300. Covilhã: MediaLivros, LabCom Books. ISBN: 9789896541521 http://www.labcom-ifp.ubi.pt/ficheiros/20141114-201403_atous_shappingnewsonline.pdf

Masip, Pere; Díaz-Noci, Javier; Domingo, David; Micó-Sanz, Josep-Lluís; Salaverría, Ramón (2010). “Investigación internacional sobre ciberperiodismo: Hipertexto, interactividad, multimedia y convergencia". El profesional de la información, v. 19, n. 6, pp. 568-576.

https://doi.org/10.3145/epi.2010.nov.02

McAdams, Mindy; Berger, Stephanie (2001). "Hypertext”. Journal of electronic publishing, v. 6, n. 3. https://doi.org/10.3998/3336451.0006.301

Murray, Denise E. (2000). “Changing technologies, changing literacy communities?”. Language learning \& technology, v. 4, n. 2, pp. 39-53.

https://doi.org/10125/25099

Nielsen, Jacob (1995). Multimedia and hypertext: The internet and beyond. San Diego: Academic Press. ISBN: 978 0125184083

Palacios, Marcos; Díaz-Noci, Javier (2007). Online journalism: Researh methods. A multidisciplinary approach in comparative perspective. Bilbao: Servicio Editorial de la Universidad del País Vasco. ISBN: 9788498601916 https://addi.ehu.es/handle/10810/15569

Paul, Nora M.; Fiebich, Christina (2005). The elements of digital storytelling. Minnesota: University of Minnesota, School of Journalism and Mass Communication's, Institute for New Media Studies.

http://mjc.umn.edu

Pérez-Marco, Sonia (2004). El concepto de hipertexto en el periodismo digital: Análisis de la aplicación del hipertexto en la estructuración de las noticias de las ediciones digitales de tres periódicos españoles (www.elpais.es, www.elmundo.es, www.abc.es). Tesis doctoral. Universidad Complutense de Madrid.

https://eprints.ucm.es/4668

Quandt, Thorsten (2008). “(No) news on the world-wide web? A comparative content analysis of online news in Europe and the United States". Journalism studies, v. 9, n. 5, pp. 717-738.

https://doi.org/10.1080/14616700802207664

Rubio-Lacoba, María (2012). “Nuevas destrezas documentales para periodistas: el vocabulario colaborativo del diario El país". Trípodos, n. 31, pp. 65-78.

http://www.tripodos.com/index.php/Facultat_Comunicacio_Blanquerna/article/view/38

Salaverría, Ramón (1999). "De la pirámide invertida al hipertexto: Hacia nuevos estándares de redacción para la prensa digital". Novática, 142, pp. 12-15.

http://dadun.unav.edu/handle/10171/5186

Salaverría, Ramón; Cores, Rafael; Díaz-Noci, Javier; Meso, Koldo; Larrondo-Ureta, Ainara (2004). “Evaluación de los ciberdiarios en las comunidades vasca y navarra". Comunicación y sociedad, v. 17, n. 1, pp. 161-189.

https://www.unav.es/fcom/communication-society/es/articulo.php?art_id=78

Salaverría, Ramón; López-García, Xosé; Limia-Fernández, Moisés; Isasi-Varela, Antonio; Pereira-Fariña, Xosé; Gago-Mariño, Manuel; Calvo-Diéguez, Rosario (2005). “Análisis comparativo de cibermedios: Lavanguardia.es, elmundo. es y elpaís.es". En: Salaverría, Ramón (coord.). Cibermedios. El impacto de internet en los medios de comunicación en España, pp. 125-143. Sevilla: Comunicación Social Ediciones y Publicaciones. ISBN: 8496082334

Spiegel, Murray R.; Stephens, Larry J. (2009). Estadística. México DF: Mc Graw-Hill. ISBN: 9789701068878

Van-der-Wurff, Richard; Lauf, Edmund (2006). "Print and online newspapers in Europe: A comparative analysis in 16 countries". Amsterdam: HetSpinhuis. ISBN: 9789055892389 